\title{
Bus Transit and Land Use: Illuminating the Interaction
}

\author{
Andy Johnson \\ Oregon Department of Transportation
}

\begin{abstract}
Attracting people to public transit in urban areas has proven to be a difficult task indeed. Recent research on the transportation-land use connection has suggested that transit use can be increased through transit-friendly land use planning. While significant evidence exists that a relationship between land use and transit is apparent, the exact nature of the relationship remains ambiguous. Despite the murky nature of the relationship, many practitioners and researchers have asserted claims regarding land use policy, namely TOD, and its effect on travel. This article examines the effect of land use, socioeconomics, and bus transit service on transit demand in the Twin Cities. The findings suggest that vertical mixed-use is important close to transit access and retail plays an important role up to a quarter mile from transit service. Population density is more important at a block-group level than block level, suggesting that density adjacent to the line may not play as critical a role as density in the larger surrounding area.
\end{abstract}

\section{Introduction}

Why do some intraurban areas attract more transit riders than others? What types of neighborhoods may induce greater transit demand? The pressure to find an answer has increased as a result of population growth, congestion, and discontent with existing transportation options. 
Despite the growing disenchantment with urban transportation, people have shown little interest in changing their ways; transit's share of work trips is still only about 4.5 percent nationally (Bureau of the Census 2000). An increase in travel times and the stability of the auto modal split suggests that people remain willing to sacrifice transportation convenience for perceived housing and neighborhood amenities. The relative low cost of auto ownership, existing cultural preferences, and transit-inefficient land use patterns only reinforce the current auto-oriented transportation situation.

The relationship between transportation and land use has received increased attention in recent years, however, the exact nature of the relationship relative to other causes remains somewhat ambiguous. Despite the ambiguous nature, proponents of transit use have focused much attention on regulating development in a manner that is more supportive of transit use, which has been coined transitoriented development (TOD). TOD proponents have blamed much of today's transportation woes on inefficient development patterns, and propose TOD as one of many contributors to a solution.

In response to this problem and policy response, this article seeks to illuminate the complex relationship between transit demand and its influences, including density, land use, socioeconomic characteristics, and transit service.

This analysis seeks to answer the question: What intraurban qualities make one area generate more or less demand for transit services? This article will first summarize the current state of transportation land use and transit literature; secondly, describe the methodology employed: next, present findings of this research; and finally expand on the findings to suggest directions of future research and public policy.

\section{State of the Literature}

\section{Transportation Land Use and Travel Behavior}

The interaction between land use and travel behavior has been studied heavily in recent years; one need look no further than the most recent studies eloquently compiled by Ewing and Cervero (2001), and Seskin and Cervero (1996). The surveyed research typically measured one of six different outcome variables: trip frequency, trip length, mode choice, cumulative person miles traveled (PMTs), vehicle miles traveled (VMTs), or vehicle hours traveled (VHTs) (Table 1). The latter three variables are different measures representing the same phenomenon-ag- 
gregate travel. Research to date has found the primary determinant of the various outputs to vary, although these concepts are interconnected.

Table 1. Output Variables from Travel and Land Use Studies

\begin{tabular}{|l|l|}
\hline Output Variable & Primary Determinants \\
\hline Trip frequency & Socioeconomic characteristics \\
Trip length & Regional accessibility \\
Mode choice & (1) Density/(2) land use \\
Cumulative PMTs/VMTs/VHTs & Regional accessibility \\
\hline
\end{tabular}

Source: Ewing and Cervero, 2001.

Generally, mode choice is affected primarily by density and land use (Table 1). This is particularly important given that local-level public policy has little direct effect on neighborhood socioeconomics or regional accessibility in the short term, while local land use regulations and neighborhood-level policy directly affect the land use and density.

In addition to density, transit ridership appears to be a function of size of the central business district (CBD) and the distance from downtown (Puskarev and Zupan 1977), as well as parking supply and price, transit service quality, pedestrian accessibility, and land use mix (Figure 1). The size of the CBD and distance from the CBD of a given stop is important because, due to the radial nature of most public transit systems, a larger CBD equates to a more accessible transit system. In addition, a larger CBD often means fewer parking spaces per person or job, which decreases the incentive to drive.

While those characteristics cited by Pushkarev and Zupan are important, parking supply, accessibility, and land use mix are also important. Recent research suggests a positive relationship between parking price and transit use (Hess 2001). This is particularly troubling to transit supporters due to the finding that free parking is enjoyed at the end of 99 percent of all trips (Cervero 1998). In addition to the economic influences of parking, parking lots, and ramps are poor land uses for inducing transit ridership. Although accessibility of transit systems has been shrinking relative to automobile accessibility for decades due to increased growth at the suburban fringe, it remains an important aspect of transit service. In addition to 
Journal of Public Transportation, Vol. 6, No. 4, 2003

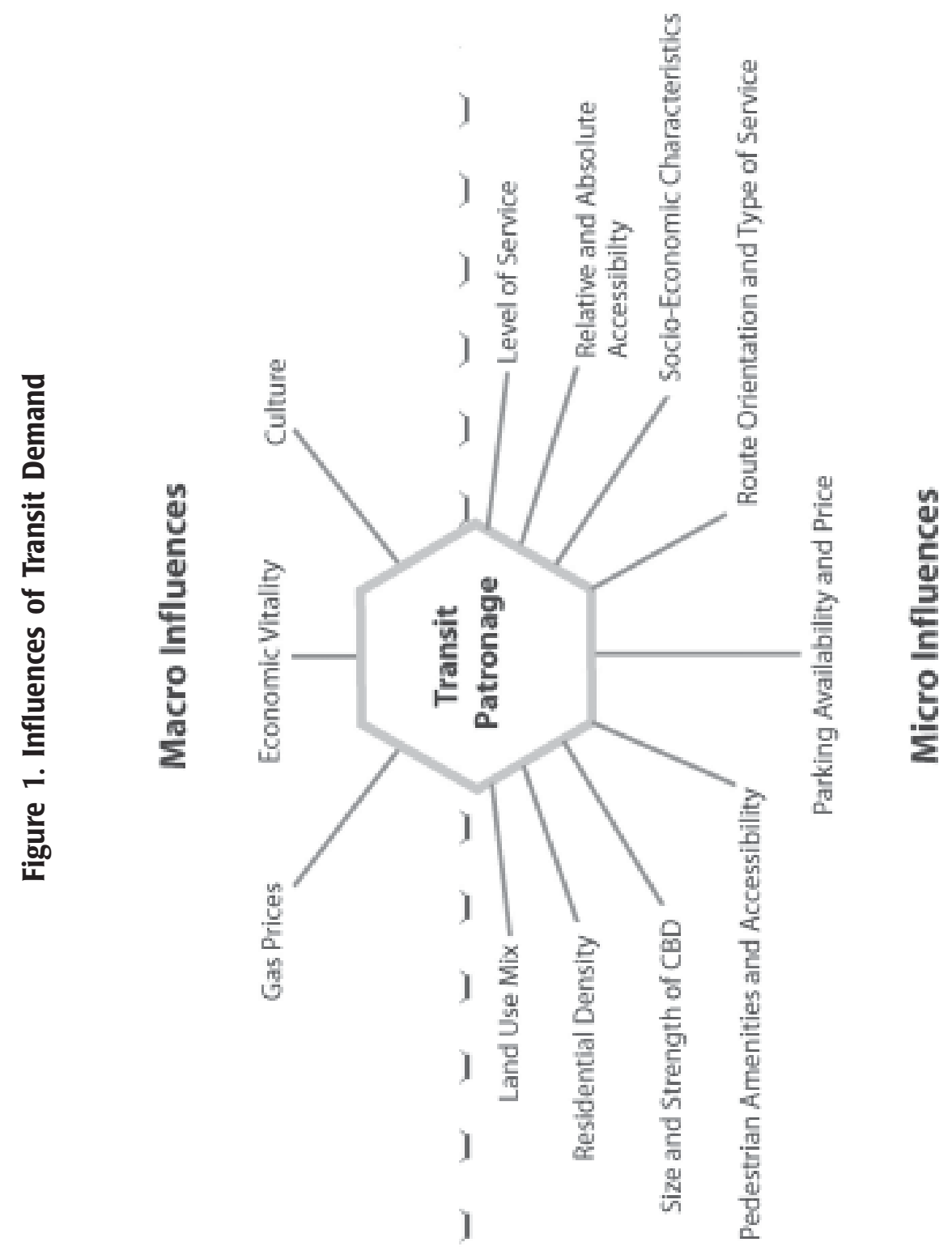


regional accessibility by means of transit, accessibility to transit is a critical factor in willingness to use transit. Due to safety concerns, perceived comfort and the effect of climate, the design of transit stops and station area amenities play an integral role in transit patronage. The importance of climate and comfort is particularly important in areas such as Minneapolis-St. Paul that often endure harsh winter weather conditions.

The effect of land use on transit is murky, although it is believed that a positive feedback loop between transit and land use exists. Transit availability increases aggregate accessibility to a given location and the attributes of the specific location determine whether people visit the location. However, the precise effects of different land uses on transit use are unclear, in part, due to the degree of interconnectedness with density and socioeconomic influences. What is clear is that the greater the intensity of land use, the greater demand for transit.

The general applicability of this research is unknown because most research has focused around rail transit, despite the prevalence of bus transit. Rail transit has become increasingly en vogue with policy-makers, the media, and researchers alike due to nostalgia (e.g., "new urbanism" or "rail revival"), potential environmental efficiency, the ease in the provision of high-frequency service, and the attractiveness of guaranteed service provision to potential developers and investors.

TOD has received increased attention in recent years. TOD's bark is perhaps bigger than its bite; it has been rarely practiced due to reluctance in the private land market and institutional barriers (Boarnet and Crane 1998). Also, there is little empirical evidence to support that individual TOD projects in a sea of single-family homes can actually sustain transit and lower auto reliance (Cervero 1998). A similar affinity toward TOD near rail transit has persisted, leaving the relationship between bus transit and TOD unclear at best.

\section{Minneapolis-St. Paul: Transit, Land Use, and History}

The Minneapolis-St. Paul metropolitan region has enjoyed significant economic vitality in recent years, and as a result significant population growth. The growth has manifest as primarily moderate- to low-density development on the urban fringe. The Minneapolis-St. Paul region has long befriended the automobile and auto-oriented development. The Metropolitan Council, the regional transit operator and land use planning agency, has responded with several public policy and marketing programs aimed at limiting geographical dispersion of residential 
growth and concentrating development along transit corridors. The Livable Communities Act was created to achieve these goals by dedicating a pool of public money that is awarded on a competitive basis for "Smart Growth" developments. The goal of the policy is to encourage developments that could be more easily served by transit in hopes of avoiding the high cost of constructing or expanding the highway system.

The regional transit system, as of 2002 exclusively bus-transit, carries about 250,000 riders per weekday. The bus system will soon be joined by an 11-mile, $\$ 750$ million light-rail transit line connecting the Minneapolis CBD, the Minneapolis-St. Paul International airport, and the Mall of America, the largest enclosed shopping mall in the United States. Metro Transit, the regional transit operator, currently operates the annual 73 million bus trips offered, primarily in the two central cities and inner-ring suburbs.

\section{Methodology}

This analysis uses the Sector 5 restructuring data obtained from the Metropolitan Council, the regional planning agency for the Minneapolis-St. Paul metropolitan area. Sector 5 is the transit planning subregion that consists of downtown Minneapolis and a radial slice running due south and southwest (Figure 2). Sector 5 contains four of the primary trip generators in the entire metro region: the Minneapolis CBD, Mall of America, International Airport, and part of the University of Minnesota Twin Cities campus. These data count only the downtown boardings onto buses that serve Sector 5 .

The attractiveness of Sector 5 in this analysis primarily lies in its relative importance and potential for increased service. It currently serves 55 percent of all transit riders, offers 38 percent of all routes, and almost 20 percent of the jobs and residents in the entire region. This is particularly important given the area only comprises about 10 percent of the geographic area.

The Sector 5 data used for this analysis consist of weekday transit boardings at bus stops in Sector 5 south of the Minneapolis CBD and west of the Mississippi River, known as areas B and C of Sector 5 (approximately $95 \%$ of all stops in the sector). Bus stops of different routes at the same location have unique ID numbers, which allowed control of route orientation and service. Only boardings were used due to the correlation between boardings and alightings; in other words, people start their return trip the same place they ended the beginning trip. This assumption was affirmed via visual confirmation of boarding and alighting maps and tables. 
Figure 2. Sector 5 Reference Map

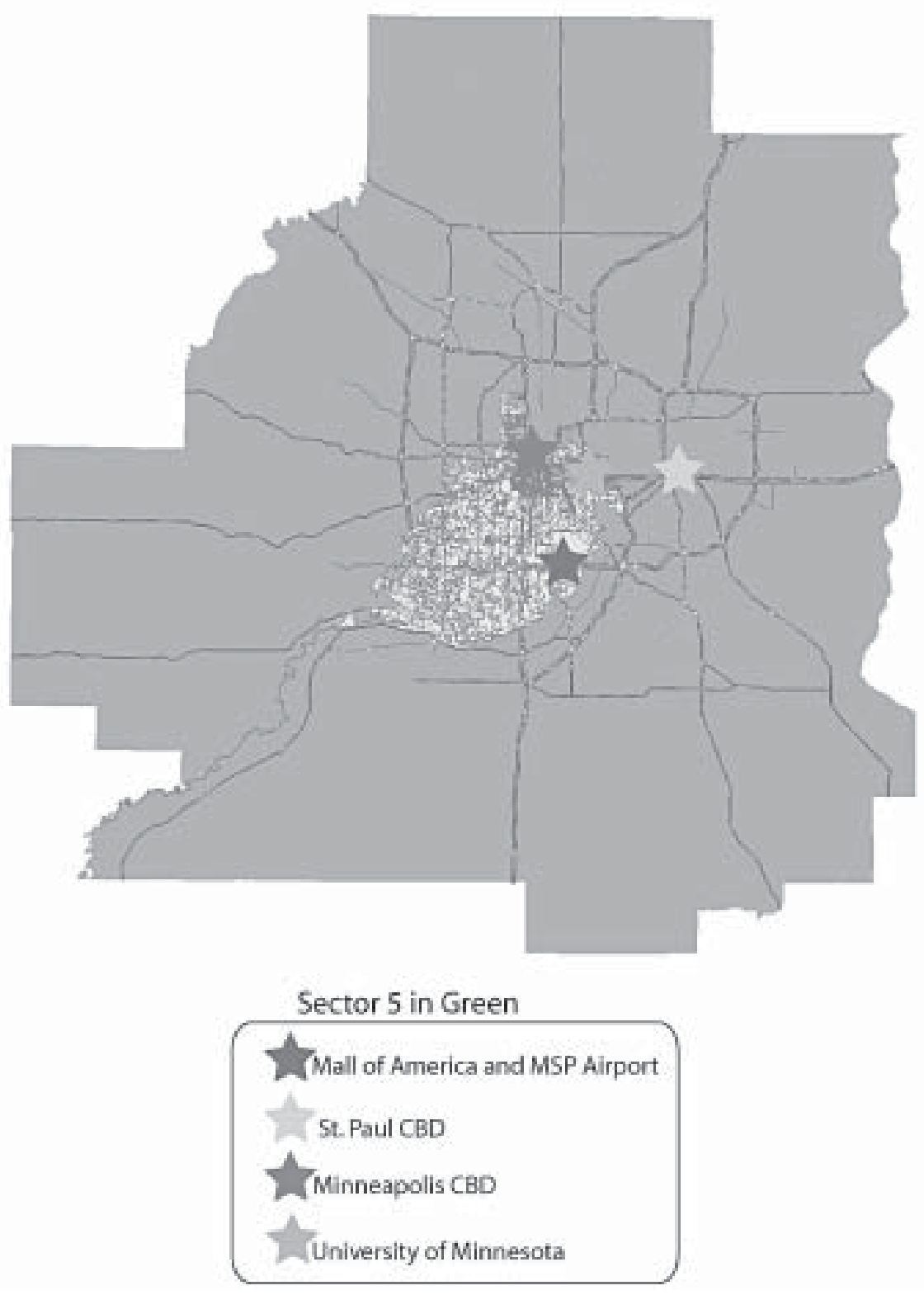


The data were compiled using GIS to select and join the relevant census and land use information with the exact location of the bus stop. The data were entered into a demand model and analyzed using a linear regression model. The land use data were simplified by combining open space, roads, and other categories and omitted from the model to allow a comparison of other land uses to relatively "dead" transit uses.

The cross-town routes are controlled for, while the radial routes feature approximately the same levels of parking availability and price. Generally all parking for all destinations on routes going away from the CBD is free, and all radial routes going toward the $\mathrm{CBD}$ terminate there.

The use of transit stops as data collection points, as opposed to individual data via travel behavior surveys, is useful for several reasons. First, transit agencies plan routes based primarily on area statistics. Similarly, land use planning can more easily create types of environments that are more conducive to transit ridership, than it can cause people to use transit. Although ideally both would be used, the small area level analysis is often overlooked, and potentially more useful to local planning agencies.

The transit demand model was created to illuminate the intraurban differences, and so many causes of demand were eliminated. For example, macro-level predictors on transit certainly affect transit use. Recent evidence shows that much of the 12 percent decline in transit ridership in the first half of the 1990s can be attributed to a sluggish economy and low gas prices, while the increased gas prices and burgeoning economy resulted in a 21 percent increase in ridership in the later half of the 1990s (Pucher 2001). Density, land use, and transit service provide stronger explanatory power given the complex decision-making process associated with mode choice within a metropolitan region. Because this analysis only looked at one market at one point in time the macro-level predictors were eliminated from the analysis. Similarly, parking prices and size of the CBD were left out because these aspects are relatively constant in the area of analysis.

The land use data were classified into basic categories: single-family, multifamily, retail-commercial, office, industrial--utility, mixed-use, and other. The other category includes open space, roads, and unused/vacant lands or spaces. Interaction variables were entered to tease out the influence that various mixes have on transit demand. Land uses were categorized into groups based whether they are primary 
job-based (office, industrial-utility), shopping-based (retail-commercial), and housing-based (single-family, multifamily).

\section{Findings}

Geography

A majority of the weekday transit demand in Sector 5 is currently located inside the City of Minneapolis, and more than 12 percent of total boardings in Sector 5 occurred in downtown Minneapolis (Table 2). Demand is clustered along Lake Street in South Minneapolis and peaks at the confluence of other transit routes (Figure 3). The ridership clustered along the Lake Street corridor, featuring crosstown service, is the area of maximum transit accessibility in Sector 5. This area is at maximum accessibility because route 21 runs the distance of Lake Street, connects to nearly every radial route in sector 5 , and offers very high-frequency service.

Table 2. Weekday Boardings by Location in Sector 5

\begin{tabular}{|lrr|}
\hline Location & Boardings & \% of Total \\
Minneapolis City & 46964 & $76.1 \%$ \\
St Paul City & 6551 & $10.6 \%$ \\
Minneapolis Suburbs & 7571 & $13.3 \%$ \\
Total Boardings in Analysis & $\mathbf{6 1 6 9 7}$ & $\mathbf{1 0 0 . 0 \%}$ \\
& & \\
Major Trip Generators & & \\
Minneapolis CBD & 8553 & $13.9 \%$ \\
Mall of America & 838 & $1.3 \%$ \\
Airport & 238 & $0.4 \%$ \\
\hline
\end{tabular}

\section{Transit Service}

The type of transit service plays a significant role in demand of a given stop (Table 3). Compared to the Urban Local service, the most prevalent service in the core area, Urban Local-Limited Stop was negatively associated with demand (Table 3). Surprisingly the level of weekday service was not a significant determinant of transit demand. To better understand the relationship between transit service and ridership, a longitudinal analysis is warranted. 
Figure 3. Total Boardings by Bus Stop in Sector 5

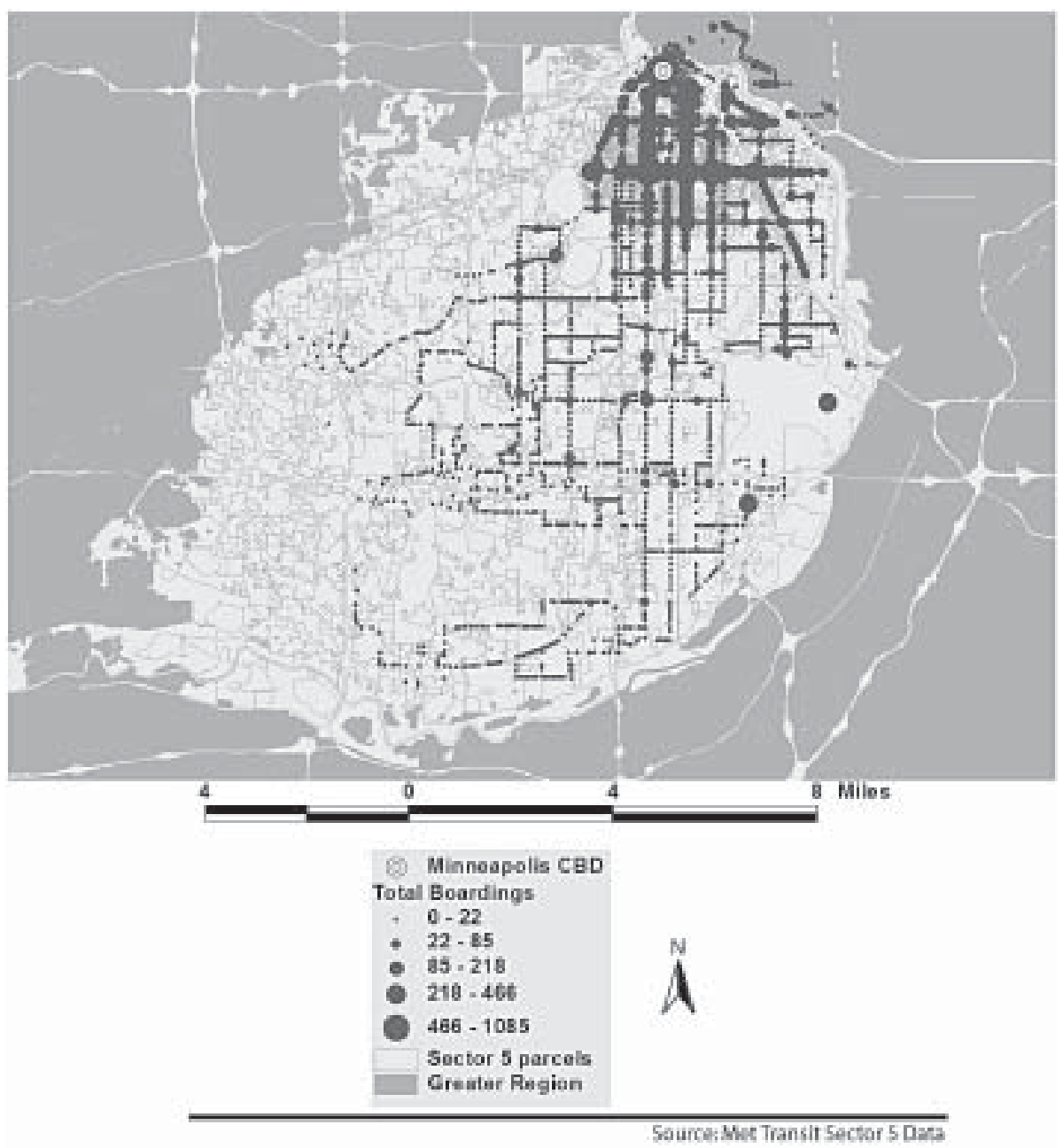

Some degree of reverse causality is likely occurring and subsequently, altering the findings. Transit planning is ideally demand responsive; the direction of causality is likely in reverse. The level of service is altered to more accurately reflect existing demand and the routes have reached a point of relative equilibrium. 
Table 3. Linear Regression Model of Transit Demand

\begin{tabular}{|c|c|c|}
\hline Independent Variables & $\begin{array}{c}\text { Beta } \\
\text { (standardized) }\end{array}$ & Sig \\
\hline (constant: $\mathrm{t}=.186$ ) & & .852 \\
\hline \multicolumn{3}{|l|}{ Transit Service (stop level attributes) } \\
\hline Buses/hour weekday & 0.026 & .149 \\
\hline Radial (1 yes/0 no) & -0.013 & .545 \\
\hline $\begin{array}{l}\text { Distance from CBD } \\
\text { (omitted Urban Local Service) }\end{array}$ & 0.009 & .788 \\
\hline Suburban Local & -0.035 & .101 \\
\hline Urban Local-Limited Stop & -0.045 & $.007 *$ \\
\hline Express Service & -0.033 & .111 \\
\hline \multicolumn{3}{|c|}{ Socioeconomic Characteristics (block-group level attributes-percentages) } \\
\hline Percent with high school diploma & -0.005 & 916 \\
\hline Percent with college degree & 0.025 & .573 \\
\hline Household income (\$) & 0.030 & .417 \\
\hline Household size & 0.014 & .720 \\
\hline Percent with access to automobile & -0.112 & $.002 *$ \\
\hline $\begin{array}{l}\text { Percent non-White } \\
\text { (omitted age cohort 30-50) }\end{array}$ & 0.037 & 276 \\
\hline Age cohort 0-16 & 0.117 & $.003 *$ \\
\hline Age cohort $16-30$ & 0.055 & .162 \\
\hline Age cohort $50-65$ & 0.018 & .476 \\
\hline Age cohort over 65 & 0.007 & .817 \\
\hline Population density (adjacent block-per sq. mile) & 0.007 & .705 \\
\hline Population density (adjacent block group-per sq. mile) & 0.115 & $.000 *$ \\
\hline \multicolumn{3}{|l|}{ Land Use (percent of parcels in a given use) } \\
\hline \multicolumn{3}{|l|}{$1 / 8$ mile radius (omitted open space, roads, and other) } \\
\hline Single-family & -0.002 & 918 \\
\hline Multifamily & -0.080 & $.009 *$ \\
\hline Mixed-use & 0.083 & $.000 \cdots$ \\
\hline Retail-commerical & 0.208 & $.000 \cdots$ \\
\hline Office & -0.008 & .802 \\
\hline Industrial-utility & -0.007 & .794 \\
\hline \multicolumn{3}{|l|}{$1 / 8$ to $1 / 4$ mile radius (omitted open space, roads, and other) } \\
\hline Single-family & 0.001 & .844 \\
\hline Multifamily & 0.072 & $.035^{*}$ \\
\hline Mixed-use & 0.006 & .701 \\
\hline Retail-commerical & 0.046 & .089 \\
\hline Office & -0.015 & 661 \\
\hline Industrial-utility & 0.005 & 844 \\
\hline \multicolumn{3}{|c|}{ Land use balance and interaction (total difference between land use area percentages) } \\
\hline Housing-jobs & -0.076 & $.007^{* *}$ \\
\hline Housing-shopping & 0.085 & $.004^{*}$ \\
\hline Shopping-jobs & 0.033 & .070 \\
\hline Adjusted R sq = , 170 & $\cdot$ & $<.05$ \\
\hline $\mathrm{F}=21.887 ; \operatorname{sig}<.000$ & $*$ & $<.01$ \\
\hline $\mathrm{N}=3362$ & $\cdots$ & $<.001$ \\
\hline
\end{tabular}




\section{Socioeconomics}

Areas of with higher percentages of the population in the $0-16$ cohort enjoy higher transit demand relative to the 30-50 cohort (Table 3). Most likely, people without a driver's license must rely on transit service, as they, theoretically, are unable to operate an automobile. Also, these areas are likely to have a larger household size and have lower levels of income available for more convenient transportation (i.e., the automobile).

The percentage of residents with access to an automobile was not surprisingly negatively associated with transit demand (Table 3 ). The greater the percentage of the population with access to an auto, the more likely someone will drive, especially given that most people enjoy abundant free or inexpensive parking in the Twin Cities. This finding seems particularly troubling given most people have access to an automobile.

The general lack of significance of socioeconomic variables suggests that some of the myths regarding urban public transportation may be easily debunked. For example, a general perception exists that transit (especially buses) is for poor people and poor areas; however, the evidence here fails to support such a notion. Similarly, the model fails to support any notion regarding public transit use as related to race/ethnicity, household size, or education.

\section{Density}

Nearly every study that has focused on transit ridership has provided evidence that density is the primary determinant of transit ridership (see Seskin and Cervero 1996 and Table 1). A study by Nelson/Nygaard (1995) showed 93 percent of the variation of transit demand in different parts of the Portland region is explained by employment and housing density, even after controlling for 40 land use and sociodemographic variables. One problem with density is that it is highly intercorrelated with other variables, as studies that have focused on density are probably missing everything that comes with it (Handy 1996a).

While population density of the block the bus stop is on is unrelated to transit demand, population density of the larger block group is significantly related to transit demand (Table 3). Many bus routes run along commercial corridors and so the lower demand associated with density at the block level is likely a result of adjacent commercial uses and while the residential areas are off the block proper. The significant relationship at the block-group level would support this notion 
and give further credence that density is of primary importance relative to transit demand.

\section{Land Use}

Multifamily residential land use was associated with lower transit demand within an eighth mile of transit stops, and associated with higher demand from an eighth mile to a quarter mile of transit stops. While the negative association near transit stations is counter to the hypothesis, the positive association within a quarter mile gives further credence to the finding that larger densities within the larger area have stronger implications on transit demand than do high densities adjacent to the line.

Transit demand is related to the percentage of mixed-use and retail-commercial land within a quarter mile of the bus stop (Table 3). The significance of adjacent vertical mixed uses to transit demand is consistent with the claims of TOD proponents and existing literature. The positive association of retail-commercial use suggests that people use transit for both nonwork and work-related travel or that employees of retail-commercial activities are more likely to use transit. Retail use is positively related to transit demand both within an eighth mile and quarter mile of the transit stop (Table 3).

\section{Land Use Interaction Effects}

Some land use interaction is evident (Table 3). The greater the difference between housing-based and employment-based land uses, the lower the demand for transit (Table 3). Jobs-housing balance is believed to be the outcome of a free market, as jobs and housing colocate to maximize access to one another (Cervero 1996). However, there is generally little evidence to support that jobs-housing balance actually occurs, and secondly, that it has any noticeable impact on transit.

A negative relationship exists between housing-shopping balance and transit ridership (Table 3). While this contradicts the standard TOD model, it is consistent with the standard gravity model. In other words, if shopping opportunities exist nearby, there is no need to travel longer distances to reach the same opportunities.

Greater opportunity is considered preferable to most because it reduces the need to travel. However, reducing the need to travel does not necessarily equate to less travel. Some people enjoy travel in the automobile (i.e., the culture of cruising); however, there is little evidence that people ride transit in that manner (except for 
tourism). In other words, a greater balance between shopping, housing, and employment-based land uses would seem to lower transit demand.

\section{Future Research Direction}

Significant advances have been achieved in transit/transportation-land use research in recent years, but much is left to be desired. Future research of this kind should focus on determining the catchment areas of the various land uses and density variables. The general rule estimates that people are willing to walk a quarter mile to transit stations. However, it remains unclear exactly how this assumption was estimated and how this number might change based on the quality of service and climate differences, as it is unlikely to be a one-size-fits-all application.

Understanding the temporal variation of transit demand would greatly enhance the ability to provide efficient and effective transit service. Travel behavior literature has created a strong foundation for understanding how people change their behavior, including mode choice, based on the time of day that they are able to travel. For example, people may be more likely to visit retail locations via transit between the hours of 5 and 7 P.M. during the week, and middle of the afternoon on the weekends. Information such as this, combined with spatial transit demand data would increase the ability of transit planners to provide the service transitdependents require, while capturing a larger share of "choice riders," or those who choose transit over other modes. This information is particularly useful given the general propensity of government funding toward the auto and auto-oriented uses and lack of funding available for transit.

Another major drawback to transit-land use analyses is the difficulty in measuring land use design and diversity measures. Diversity measures have employed entropy measures and a dissimilarity index (Cervero and Kockelman 1997; Frank and Pivo 1994), and estimated the distances between several different retail commercial uses and residential units (Handy 1996b). While these measures are innovative uses of existing data, they leave much to be desired. To truly illuminate the complex causes of transit demand, a much more robust statistical foundry is needed. Considering the difficulty in funding such comprehensive data collection and entry, and slim funding to transit agencies, large data enhancement is as unlikely as it is necessary. Similarly, researchers have made significant progress on operationalizing other aspects of land use in recent years (Evans et al. 1997; Loutzenheiser 1997; Cervero and Kockelman 1997; Krizek 2002; Hess et al. 2002). Despite these improvements, highlighting the effect of pedestrian environmental 
factors (street lighting, sidewalk width, timing of crosswalks, on-street parking) or land use factors (setbacks, presence of front porches, windows facing the front), and possibly even social connectivity (tightness of community, social organizations) could greatly enhance the collective understanding of the effect of design and diversity on travel behavior and transit ridership.

Also, the existing measures fail to address the interaction between different land uses and the effect of interaction on travel behavior and transit use. The use of a heterogeneity measures assumes that every mix is the same, which is inaccurate (Hess et al. 2002). Measuring land use complementarity is an important step toward crafting "transit-friendly" land use plans and regulations, as well as testing and increasing the effectiveness of TOD.

Finally, a combination of a cross-sectional and longitudinal analyses, as well as both area and individual level data, will provide a stronger foundation to predict the effect changes in service have on ridership and development patterns near transit stops. In addition, such an analysis would help control for self-selection, and would provide insight toward the effect that various levels of transit service change have on residential demand near transit stops.

\section{Conclusions and Policy Implications}

\section{Land Use Implications}

The results of this research suggest there are three primary means available to planners to enhance transit ridership through land use planning: increase residential density in the areas near transit corridors, concentrate mixed-use development within an eighth mile of the transit corridors, and channel a greater proportion of the retail development within a quarter mile of transit lines. In fact, this analysis suggests that transit planners would increase ridership to a greater degree through catalyzing retail, mixed-use and multifamily development than increasing transit service.

While the results of the model provide support to TOD, some minor changes to the traditional TOD model are proposed. The clustering of vertical mixed-uses and retail-commercial near transit stops and higher density residential within a quarter mile of transit stops remains consistent with the traditional Calthorpe TOD model. However, existing literature in conjunction with this analysis would not promote office use in neighborhoods, but would rather cluster office uses in the CBD. Although the model in Figure 4 is crude, it provides a visual representation of the land use findings from this analysis. 
Journal of Public Transportation, Vol. 6, No. 4, 2003

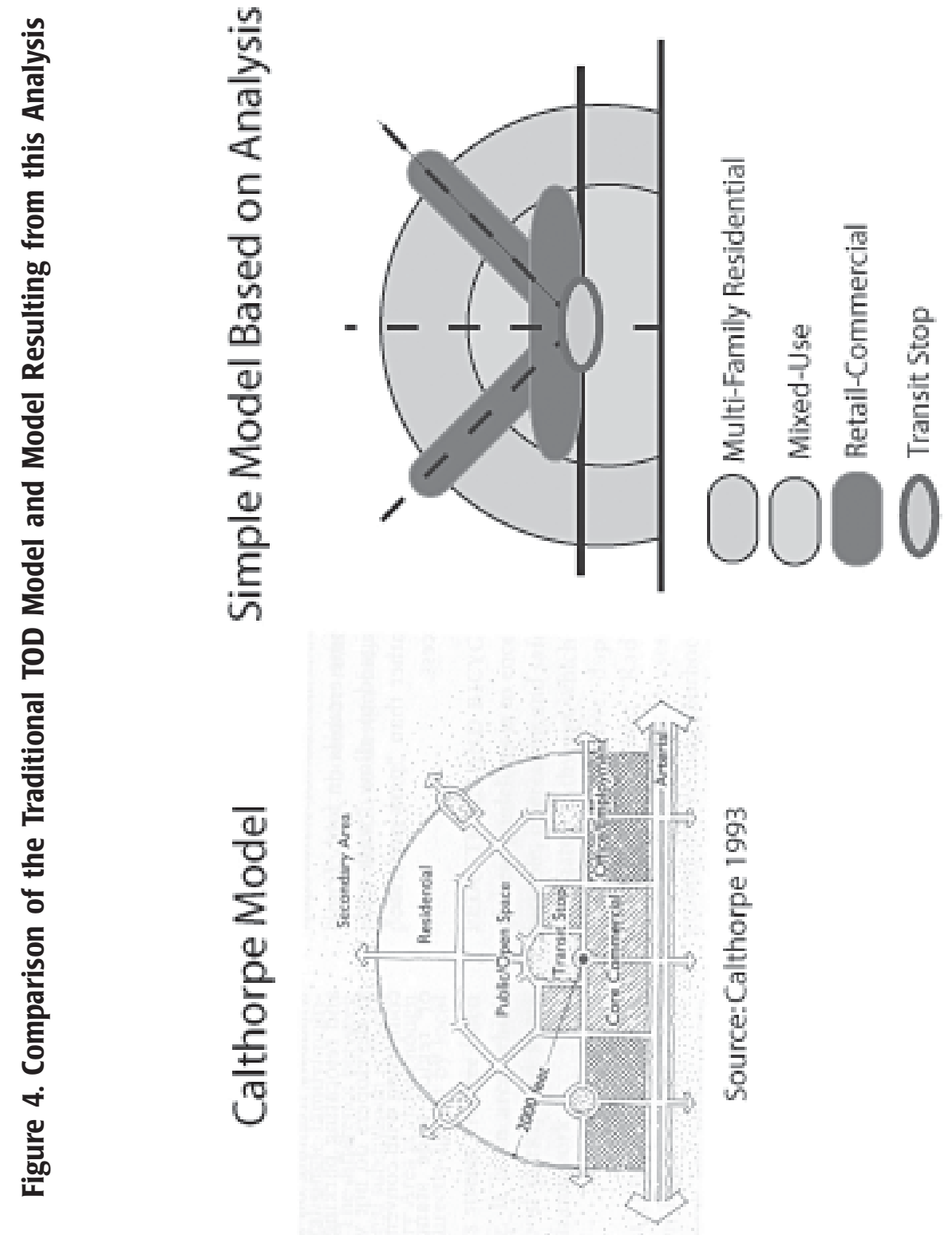


Despite the auspiciousness of land use planning as a transit ridership tool, it is difficult to determine the degree self-selection affects these results. Most likely those who choose to ride transit choose their residential location based on that premise. In other words, changing the land use or density around a given bus stop does not necessarily make people in the vicinity more likely to use transit

While substantial improvements are needed in the world of research, even greater improvements are needed in the world of practitioners. Those ideas that have been reinforced by numerous studies (i.e., intensity of use and limited parking result in higher transit ridership) have yet to be implemented by planning agencies to any significant degree. To increase ridership to the point that an effect on congestion and the built environment is evident, strong land use planning, investment in transit, and political will are necessary.

Finally, while these results illuminate the causes of transit demand, the effect is quite small. Predicting complex human behavior is a problem that has plagued the social sciences since their development. While some of these results are statistically significant, they fail to explain much of the variation associated with transit demand. The result of implementing these results will increase transit demand, but only marginally, which is evident given the small coefficients associated with these predictors. However, the results, and subsequent policies prescribed, should be weighed in light of the alternatives. The effect of these contributors to transit demand may be small, but they are better than the continuation of the omnipresent auto-oriented environment in the United States.

As urban America becomes increasingly disgruntled with its transportation options, public officials will have their feet held to the policy flame in order to make changes. At some point politicians and researchers will be forced to convince the American public to change or balance their preferences for accessibility and housing-related amenities. Enhanced research, and putting what is known into practice, will go a long way toward doing so. 
Journal of Public Transportation, Vol. 6, No. 4, 2003

\section{References}

Boarnet, M. G., and R. Crane. 1998. Public finance and transit-oriented planning: New evidence from Southern California. Journal of Planning Education and Research 17: 206-219.

Bureau of the Census. 2000. STF3A summary files. Washington DC.

Calthorpe, P. 1993. The next American metropolis: Ecology, community and the American dream. New York: Princeton University Press.

Cervero, R. 1998. The transit metropolis: A global inquiry. Washington DC: Island Press.

Cervero, R. 1996. Jobs-housing balance revisited: Trends and impacts in the San Francisco Bay Area. Journal of the American Planning Association 62(4): 492512.

Cervero, R., and K. Kockelman. 1997. Travel demand and the 3 Ds: Density, diversity and design. Transportation Research D 2(3): 199-219.

Evans, John E., V. Perincherry, and G. B. Douglas III. 1997.Transit friendliness factor: Approach to quantifying transit access environment in transportation planning model. Transportation Research Record 1604: 32-39

Ewing, R., and R. Cervero. 2001. Travel and the built environment. Transportation Research Record 1780: 87-114.

Frank, L. D., and G. Pivo. 1995. Impacts of mixed use and density on utiliation of three modes of travel: Single-occupant vehicle, transit and walking. Transportation Research Record 1466: 44-52.

Handy, S. 1996a. Travel behavior issues related to neo-traditional developmentA review of the research. Presented at TMIP Conference on Urban Design, Telecommuting, and Travel Behavior. FFWA, U.S. Department of Transportation.

Handy, S. 1996b. Understanding the link between urban form and nonwork travel behavior. Journal of Planning Education and Research 15:183-198.

Hess, D. 2001. Effect of free parking on commuter mode choice: Evidence from travel diary data. Transportation Research Record 1753: 35-42. 
Hess, P. M., A. V. Moudon, et al. 2002. Measuring land use patterns for transportation research. Transportation Research Record 1780: 17-24.

Krizek, K. 2002. Operationalizing neighborhood accessibility for land use travel behavior research and regional modeling. Journal of Planning Education and Research.

Loutzenheiser, D. R. 1997. Pedestrian access to transit: Model of walk trips and their design and urban form determinants around BART stations. Transportation Research Record 1604: 40-49.

Nelson/Nygaard Consulting Associates. 1995. Land use and transit demand: The transit orientation index, Chapter 3. Primary Transit Network Study. Portland, OR: Tri-Met.

Pucher, J. 2001. Renaissance of public transport in the United States? Transportation Quarterly 56(1): 33-49.

Puskarev, B., and J. Zupan. 1977. Public transportation and land use policy. Bloomington, IN: University Press.

Seskin, S., and R. Cervero. 1996. Transit and urban form. Washington DC: Federal Transit Administration.

\section{About the Author}

ANDY JoHnson (onejmd@yahoo.com) is a long-range transportation planner for the Oregon Department of Transportation. He is a graduate of the master's in Urban and Regional Planning program at the University of Minnesota and the Center for Transportation Studies. Mr. Johnson worked as a planning consultant for the Ventura Village neighborhood on the Southside of Minneapolis and been involved with transit, land use, and travel behavior research at the University of Minnesota. He was recently awarded the Barbara Lukermann Service to Planning Award for his efforts in connecting the planning program to the larger community. 